\title{
Attribution of aerosol light absorption to black carbon, brown carbon, and dust in China - interpretations of atmospheric measurements during EAST-AIRE
}

\author{
M. Yang, S. G. Howell, J. Zhuang, and B. J. Huebert \\ Department of Oceanography, University of Hawaii, Honolulu, Hawaii, USA \\ Received: 4 March 2008 - Published in Atmos. Chem. Phys. Discuss.: 6 June 2008 \\ Revised: 9 March 2009 - Accepted: 11 March 2009 - Published: 20 March 2009
}

\begin{abstract}
Black carbon, brown carbon, and mineral dust are three of the most important light absorbing aerosols. Their optical properties differ greatly and are distinctive functions of the wavelength of light. Most optical instruments that quantify light absorption, however, are unable to distinguish one type of absorbing aerosol from another. It is thus instructive to separate total absorption from these different light absorbers to gain a better understanding of the optical characteristics of each aerosol type. During the EAST-AIRE (East Asian Study of Tropospheric Aerosols: an International Regional Experiment) campaign near Beijing, we measured light scattering using a nephelometer, and light absorption using an aethalometer and a particulate soot absorption photometer. We also measured the total mass concentrations of carbonaceous (elemental and organic carbon) and inorganic particulates, as well as aerosol number and mass distributions. We were able to identify periods during the campaign that were dominated by dust, biomass burning, fresh (industrial) chimney plumes, other coal burning pollution, and relatively clean (background) air for Northern China. Each of these air masses possessed distinct intensive optical properties, including the single scatter albedo and Ångstrom exponents. Based on the wavelength-dependence and particle size distribution, we apportioned total light absorption to black carbon, brown carbon, and dust; their mass absorption efficiencies at $550 \mathrm{~nm}$ were estimated to be 9.5, 0.5 (a lower limit value), and $0.03 \mathrm{~m}^{2} / \mathrm{g}$, respectively. While agreeing with the common consensus that black carbon is the most important light absorber in the mid-visible, we demonstrated that brown carbon and dust could also cause significant absorption, especially at shorter wavelengths.
\end{abstract}

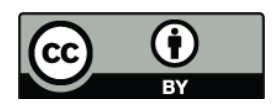

Correspondence to: $\mathrm{M}$. Yang (mingxi@hawaii.edu)

\section{Introduction}

Aerosols scatter and absorb shortwave solar radiation, generally resulting in cooling and warming of the planet, respectively, if the two phenomena are treated independently. When globally averaged, the vast amounts of highly scattering sulfate particles in the atmosphere (a product of fossil-fuel combustion) are believed to have a net cooling effect on the earth's surface. On the other hand, strongly absorbing soot carbon aerosols lead to a warming of the planet (Solomon et al., 2007). Other important light absorbing aerosols in the atmosphere include brown carbon and mineral dust.

Aerosol absorption can be represented by the classic BeerLambert Law, which relates the intensity of incident $\left(I_{0}\right)$ and outgoing $(I)$ light by an exponential:

$I=I_{0} e^{-\alpha l c}$

where $\alpha$ is the absorption cross section, $l$ is the path length, and $c$ is the concentration. The product of $\alpha$ and $c$ in the exponent is defined as the absorption coefficient $\left(b_{a p}\right)$, which can be measured by in situ instruments such as the aethalometer in units of inverse length. If $c$ represents the mass concentration of absorbing particles (e.g. $\mu \mathrm{g} / \mathrm{m}^{3}$ ), $\alpha$ is then the mass absorption cross-section, or mass absorption efficiency (MAE), often in units of $\mathrm{m}^{2} / \mathrm{g}$; MAE can vary greatly depending on the type of light absorbers. Analogously, the scattering coefficient $\left(b_{s p}\right)$ is the product of the scattering cross section and the concentration of scattering particles. Since all aerosols scatter light, scattering coefficient is often used as a proxy for particle concentration.

The fraction of light extinction (sum of scattering and absorption) due to scattering is defined as the single scatter albedo $\left(\omega_{0}\right.$, or SSA $)$ - an intensive property determined by the particle composition while independent of the total aerosol concentration:

$\omega_{0}=b_{s p} /\left(b_{a p}+b_{s p}\right)$

Published by Copernicus Publications on behalf of the European Geosciences Union. 
The single scatter albedo is an important factor in controlling whether an aerosol layer has a cooling or warming effect. Non-absorbing particles (e.g. ammonium sulfate) have $\omega_{0}$ of unity, whereas a lower $\omega_{0}$ implies more absorption.

Aerosols scatter and absorb light differently depending on the particle size $\left(D_{p}\right)$ relative to the wavelength of light $(\lambda)$. For a given aerosol composition (which determines the refractive index), the Mie scattering theory can be used to approximate the amount of scattering and absorption when $D_{p}$ and $\lambda$ are known, assuming the particle is spherical. Since most atmospheric aerosols are small, their absorption tends to be higher near the ultraviolet (UV) than near the infrared (IR). Absorption is often parameterized as proportional to $\lambda^{-\AA}$, where the exponent, $\AA$, is the absorption Ångstrom exponent. An analogous expression can be written for the wavelength-dependence of scattering.

Soot carbon, or combustion-generated carbonaceous aerosol that absorbs light strongly over the entire visible spectrum, is traditionally viewed as the most important light absorber for solar radiation (Hansen et al., 1984; Penner et al. 1993). Soot is monitored either optically or chemically. The optical method relies on light absorption; the corresponding operational definition for soot is black carbon (BC). The chemical (thermal) method measures the mass concentration of total carbon, in which the portion that is refractory and does not volatilize below $\sim 400^{\circ} \mathrm{C}$ in air is termed elemental carbon (EC) (Birch and Cary, 1996); the volatile portion is assumed to be organic carbon (OC). Since BC and EC refer to somewhat different fractions of absorbing carbon, distinctions in these operational definitions need to be carefully considered when relating optical and chemical measurements of soot, such as when calculating the mass absorption efficiency.

Freshly emitted soot particles from combustion have graphite-like sheet structures that fold among themselves to form agglomerates of primary spherules around $20 \mathrm{~nm}$ in diameter (Bond and Bergstrom, 2006), which shortly after emission coagulate and form loose aggregates. Because they are usually small, soot particles fit within the Rayleigh scattering regime for near-visible wavelengths. In this regime, absorption follows a theoretical $\lambda^{-1}$ relationship, implying a wavelength-independent imaginary component of the refractive index; this for soot is supported by the Band-gap theory (Bond and Bergstrom, 2006). Many laboratory observations have shown that soot has an absorption Ångstrom exponent of one in the solar spectrum (Bergstrom et al., 2002; Schnaiter et al., 2003; Kirchstetter et al., 2004). Previous experiments from our group also demonstrated that within the range measured by the seven-wavelength aethalometer $(370$ to $950 \mathrm{~nm}$ ), $\AA \approx 1$ was obtained when fitting absorption with a power law for air masses dominated by soot carbon (Kline et al., 2004).

Modeling studies have suggested that total soot absorption is increased by $\sim 30 \%$ as a result of the aforementioned ag- gregation compared to singular primary spherules (Fuller et al., 1999), possibly due to the effect of multiple scattering. Bond and Bergstrom (2006) amassed literature results and recommended a mass absorption efficiency of $7.5 \pm 1.2 \mathrm{~m}^{2} / \mathrm{g}$ for fresh soot aggregates at $550 \mathrm{~nm}$. Other aerosols can also be externally or internally mixed with soot. Fuller et al. (1999) and Bond et al. (2006) have shown that a complete encapsulation of a soot core with non-absorbing organic or inorganic condensates might result in an absorption enhancement of up to $30 \sim 50 \%$.

More recently, carbonaceous particles that are optically in between the strongly absorbing soot carbon and nonabsorbing organic carbon have also been shown to be significant, and they are operationally defined as brown carbon. Formed by inefficient combustion of hydrocarbons (e.g. smoldering) and also by photo-oxidation of biogenic particles, brown carbon encompasses a large and variable group of organic compounds, and may include humic substances, polyaromatic hydrocarbons, and lignin (Andreae and Gelencser, 2006). Due to the presence of resonant ring structures, most absorption by brown carbon takes place in the UV, though the lowered bond energy of the conjugated bonds causes a tail of absorption in the short visible wavelengths. Consequently, the absorption Ångstrom exponent of brown carbon is larger than that of soot.

Thus far, published absorption efficiencies and Ångstrom exponents for "brown carbon" have been inconsistent. Hoffer et al. (2006) extracted humic-like substances (HULIS) with water from the fine fraction of biomass burning aerosols and found an absorption Ångstrom exponent of 6 7 and a mass absorption efficiency of $\sim 0.03 \mathrm{~m}^{2} / \mathrm{g}$ at $532 \mathrm{~nm}$. Kirchstetter and Novakov (2004) isolated organic carbon with acetone and found mass absorption efficiencies of $0.9 \mathrm{~m}^{2} / \mathrm{g}$ at $500 \mathrm{~nm}$ and $0.6 \mathrm{~m}^{2} / \mathrm{g}$ at $550 \mathrm{~nm}$ for the extract $(\AA>4$ over this short range of wavelengths). Clarke et al. (2007) isolated "refractory organic carbon" from biomass burning aerosols with a thermal method and approximated brown carbon absorption as the difference between total and extrapolated BC absorption; from these estimates they obtained mass absorption efficiencies of $0.52 \mathrm{~m}^{2} / \mathrm{g}$ at $470 \mathrm{~nm}$ and $0.19 \mathrm{~m}^{2} / \mathrm{g}$ at $530 \mathrm{~nm}$ ( $\AA>8$ over this short range of wavelengths). It is unsurprising to see such discrepancies in literature results because a variety of aerosols were measured using several different techniques, with each derived concentration and light absorption corresponding to a different fraction of carbonaceous particles.

Optical properties of eolian dust aerosols are determined by their mineralogical origins as well as physical modifications once airborne. Ferric iron oxides such as hematite and goethite, when internally mixed with clay minerals, result in significant dust absorption in the UV/visible (Sokolik and Toon, 1999). As with brown carbon, dust absorption in the solar spectrum decreases rapidly with increasing wavelength. Alfaro et al. (2004) found that for Gobi (China), Sahara (Tunisia), and Sahel (Niger) dust, the 
mass absorption efficiencies ranged from $0.01 \sim 0.02 \mathrm{~m}^{2} / \mathrm{g}$ at $660 \mathrm{~nm}$ and $0.06 \sim 0.12 \mathrm{~m}^{2} / \mathrm{g}$ at $325 \mathrm{~nm}(\AA \approx 3$ over this range), while an absorption Ångstrom exponent of 2.6 can be calculated from the report of Fialho et al. (2006).

Particles generated from diesel combustion are conventionally used as the laboratory surrogate for black carbon. Much less is known about coal-burning aerosols, even though coal combustion accounts for roughly half of the BC in the atmosphere (Bond et al., 2002). The EAST-AIRE campaign in 2005 provided us an opportunity to study the optical and chemical properties of, among others, coal-derived aerosols, which are ubiquitous in much of China and other developing countries. Coal generally contains more impurities and water than diesel fuel. We thus expect the combustion of coal to be less efficient and complete than the combustion of higher-grade fossil fuels, resulting in relatively more brown carbon that is less absorbing than $\mathrm{BC}$ per unit mass but has a greater absorption Ångstrom exponent. In many households, furnaces are partially choked on purpose to moderate temperature and prolong burning time (personal experience); this inefficient way of burning coal might further increase amount of brown carbon generated. For residential cooking and heating, honeycomb coal briquettes are preferred because they burn more predictably and produce less smoke than unmodified coal. These briquettes are made by first binding powdered coal with clay when wet; the mixture is then molded into cylinders with many cylindrical cavities, resembling a honeycomb. After the coal is burned off, briquettes retain their structural integrity and appear orange in color, suggesting that the clay binder contains ferric oxides. Our filters that were exposed to coal-dominated pollution for $\sim 12 \mathrm{~h}$ appeared to have the same orange color after thermal analysis as burned coal briquettes. It is possible that such iron-rich clay materials can be liberated from the briquette matrix as coarse, light absorbing aerosols. The emission of light absorbing particles other than BC is likely the cause for the wide range of absorption Ångstrom exponents observed for coal-derived aerosols (1-2.9, Bond et al., 2002).

Ambient aerosol absorption is often normalized by the concentration of EC to approximate the EC mass absorption efficiency. While this approach might be valid in areas dominated by fresh soot emission, dividing total absorption by the soot concentration is misleading when other light-absorbers are also present. In those more complex environments, if we can separate and attribute total light absorption to different absorbing aerosols, given their respective mass concentrations, we can calculate MAE specific to each aerosol type present.

\section{Experimental}

EAST-AIRE took place in part between 2 March and 26 March 2005 at the Institute of Atmospheric Physics (IAP) research facility $\sim 2 \mathrm{~km}$ east of Xianghe, China
(Li et al., 2007). About $70 \mathrm{~km}$ east of Beijing, our site was heavily polluted due to both local and distant sources of fossil fuel combustion, vehicular and industrial emissions, and also occasional dust and biomass fires. While coal burning was technically forbidden in the town of Xianghe, nearby residences and a number of small factories neighboring the IAP facility used coal. The boiler of the IAP facility itself burned coal also; a cyclone was installed to remove large particles - an implementation that most other boilers lacked. We could see over 20 active chimneys in all directions from our sampling site. Direct plumes from these chimneys, many yellowish in color, almost always contained particle number concentrations over $10^{4} \mathrm{~cm}^{-3}$. Given the density and proximity of sources, back-trajectories to identify specific emissions were not attempted.

The ambient temperature was around $0^{\circ} \mathrm{C}$ at the start of the campaign and warmed up to $\sim 20^{\circ} \mathrm{C}$ towards the end. The ambient relative humidity was rather low $(<40 \%$ on average) and invariable. The sample air was drawn into a heated room that was quite dry also. Due to its inland geographical location, there was no observable marine influence. Brisk winds $(\sim 10 \mathrm{~m} / \mathrm{s})$ usually came from the west/northwest (the direction of Beijing and distant mountain ranges), which brought along relatively clean air and occasionally mineral dust particles. In contrast, much gentler winds from the southeast (the direction of Xianghe town) carried the highest levels of air pollutants. The air was often particularly dirty in the morning when the winds were weak and the inversion layer was low, as emissions from anthropogenic activities including morning traffic, cooking, and heating were trapped near the ground. Sometimes a second (and somewhat smaller) peak in atmospheric pollutants was also observed in the evening traffic and cooking hours.

\subsection{Absorption and scattering measurements}

We used a Radiance Research (Seattle, WA) Particle Soot Absorption Photometer (PSAP) that recorded absorption at a single wavelength $(567 \mathrm{~nm})$ every $5 \mathrm{~s}$ and a TSI (St. Paul, MN) Model 3563 integrating nephelometer that recorded scattering at 450,550 , and $700 \mathrm{~nm}$ every second. The PSAP and the nephelometer shared an impactor that switched from submicron particle sampling to total particle sampling every $10 \mathrm{~min}$. We adjusted raw scattering coefficients from the nephelometer for angular truncation according to Anderson and Ogren (1998). Due to the high particle concentration, changing the PSAP filter every time the transmission dropped below $70 \%$ (as recommended by Bond et al., 1999) was often not possible. Instead, we opted for a filter change whenever the transmission was near 50\%; absorption measurements when the corresponding transmission levels dropped below 50\% were later discarded. We corrected our raw absorption coefficients from the PSAP to $550 \mathrm{~nm}$ for loading, apparent absorption, and multiple scattering artifacts according to Bond et al. (1999). 
By alternating between total and submicron sampling with an impactor, we were able to look at PSAP absorption and nephelometer scattering for fine and coarse (total - fine) particles separately. To generate a continuous time-series of total scattering, the ratio of total to submicron scattering determined from adjacent segments was applied to each submicron scattering segment. Complete times-series of submicron scattering and total/submicron PSAP absorption were generated analogously.

To cover a greater range of wavelengths than the PSAP, we used a Magee Scientific (Berkley, CA) AE31 aethalometer to record absorption sequentially at $370,470,520,590$, 660,880 , and $950 \mathrm{~nm}$ in 2-min cycles. The aethalometer was operating in an automated mode, under which the filter tape advances when the attenuation at $370 \mathrm{~nm}$ reaches 75 . Attenuation $(\mathrm{ATN})$ here is defined as $100 * \operatorname{Ln}\left(I_{o} / I\right)$, where $I_{o}$ and $I$ are light intensities through portions of the filter that are clear of and laden with aerosols, respectively. The flow rate of the aethalometer was kept near the lower limit required by the instrument ( $1.2 \mathrm{LPM})$ due to the high concentration of particles.

Following calibration schemes from Bond et al. (1999), Weingartner et al. (2003), and Arnott et al. (2005), we corrected absorption coefficient from the aethalometer for the loading artifact of absorbing particles, apparent absorption by purely scattering particles, and multiple scattering by the filter matrix using the following equation (Yang, 2007):

$b_{a p}(t, \lambda)=\left(b_{\text {aeth }}(t, \lambda)-F_{a a}(\lambda) \times b_{s p}(t, \lambda)\right) \frac{F_{\text {load }}(t, \lambda)}{F_{m s}(\lambda)}$

At a given time $(t)$ and wavelength $(\lambda)$, the corrected absorption coefficient $\left(b_{a p}\right)$ is related to raw absorption coefficient from the aethalometer $\left(b_{\text {aeth }}\right)$ by three wavelength-dependent correction factors. $F_{a a}$ is the apparent absorption correction factor adopted from Arnott et al. (2005). $F_{m s}$ is the multiple scattering correction factor taken from Weingartner et al. (2003) for coated soot. To develop $F_{\text {load }}$, the loading correction factor, we first followed the parameterization from Weingartner et al. (2003) and assumed that raw absorption coefficient from the aethalometer is linearly related to the log of attenuation. When the filter tape gets heavily loaded, ATN correspondingly increases while $b_{\text {aeth }}$ artificially decreases until the next tape advancement, resulting in discontinuities across filter changes usually observed when the aerosols are relatively constant (e.g. at $\sim 23: 00$ UTC in Fig. 1). On timescales of minutes, variability in ambient absorption is mostly due to concentration change (driven by atmospheric dynamics) rather than composition change (driven by chemistry) in the aerosols. We can likely remove much of the variability in absorption by taking into account the change in concurrent scattering from the nepheometer $\left(b_{s p}\right)$. By assuming that the remaining variability in absorption (due to aerosol composition change) is negligible (i.e. constant $\omega_{0}$ ) on short timescales, we can then apply the proportionality between $b_{\text {aeth }}$ and $\operatorname{Ln}(\mathrm{ATN})$ :

$$
F_{\text {load }}(t, \lambda)=\left(R_{f}(\lambda)-1\right) \frac{\operatorname{Ln}(\operatorname{ATN}(t, \lambda))-\operatorname{Ln}(\operatorname{ATN}(A, \lambda))}{\operatorname{Ln}(\operatorname{ATN}(B, \lambda))-\operatorname{Ln}(\operatorname{ATN}(A, \lambda))}
$$

Here $A$ and $B$ designate the first point after an aethalometer tape advancement and the last point before that advancement, respectively. At a given wavelength, $R_{f}$ is defined as $R_{a} / R_{s}$, where $R_{a}=b_{\text {aeth }}(A) / b_{\text {aeth }}(B)$ and $R_{s}=b_{s p}(A) / b_{s p}(B)$. Scattering from the nephelometer was fitted to the seven wavelengths of the aethalometer using the scattering Ångstrom exponent, which was determined from the slope of $\log \left(b_{s p}\right)$ vs. $\log (\lambda)$. A loading correction without taking scattering into account (i.e. forcing $b_{\text {aeth }}(A)$ and $b_{\text {aeth }}(B)$ to be the same) is only valid when the aerosols are completely non-changing and should not be applied to ambient measurements (e.g. at $\sim 22: 00$ UTC in Fig. 1). The quality of Eq. (4) was assessed by plotting the respective $b_{a p} / b_{a p}(A)$ against $\operatorname{Ln}($ ATN $)$, which resulted in a largely ATN - independent ratio of unity on a campaign average. Please refer to Yang (2007) for a much more detailed description of the aethalometer correction and also a comparison of this correction scheme to ones previously published. Corrected absorption from the aethalometer adjusted to $550 \mathrm{~nm}$ by the absorption Ångstrom exponent showed excellent agreement with absorption from the PSAP (within 5\%).

\subsection{Elemental and organic carbon measurements}

We measured elemental carbon and organic carbon using a Sunset Laboratory Inc. (Forest Grove, OR) Semi-continuous OCEC Carbon Aerosol Analyzer. Samples were collected and analyzed hourly, except 07:00-08:00 and 19:0020:00, when filters were changed and calibrations were run. They started on the hour and lasted $40 \mathrm{~min}$, allowing $20 \mathrm{~min}$ for analysis. A passive diffusion denuder was placed before the OCEC instrument to remove any vapor-phase organic carbon. The instrument volatilizes particulate carbon thermally and oxidizes it to carbon dioxide $\left(\mathrm{CO}_{2}\right)$, which is monitored by a non-dispersive infrared (NDIR) detector. Since a portion of $\mathrm{OC}$ is charred to an absorbing EC-like material instead being directly oxidized to $\mathrm{CO}_{2}$, the instrument relies on the change in transmission of a laser through the filter to account for the pyrolysis of (originally) non-absorbing OC. The split-point between EC and OC is defined as the time when the laser transmission returns to its initial level (after the charred material is burnt off). This determination of the split-point is based on the assumption that non-native and native EC have the same thermal stability and optical properties, which might not be true if any liquid-like brown carbon was present (Subramanian et al., 2007). Interested readers may refer to Huebert et al. (2004) and Kline et al. (2004) for much more detailed descriptions on combustion stages, blanking procedures, and the determination of the split-point.

We also obtained size-segregated concentrations of EC and OC from an MSP (Minneapolis, MN) Micro-orifice 

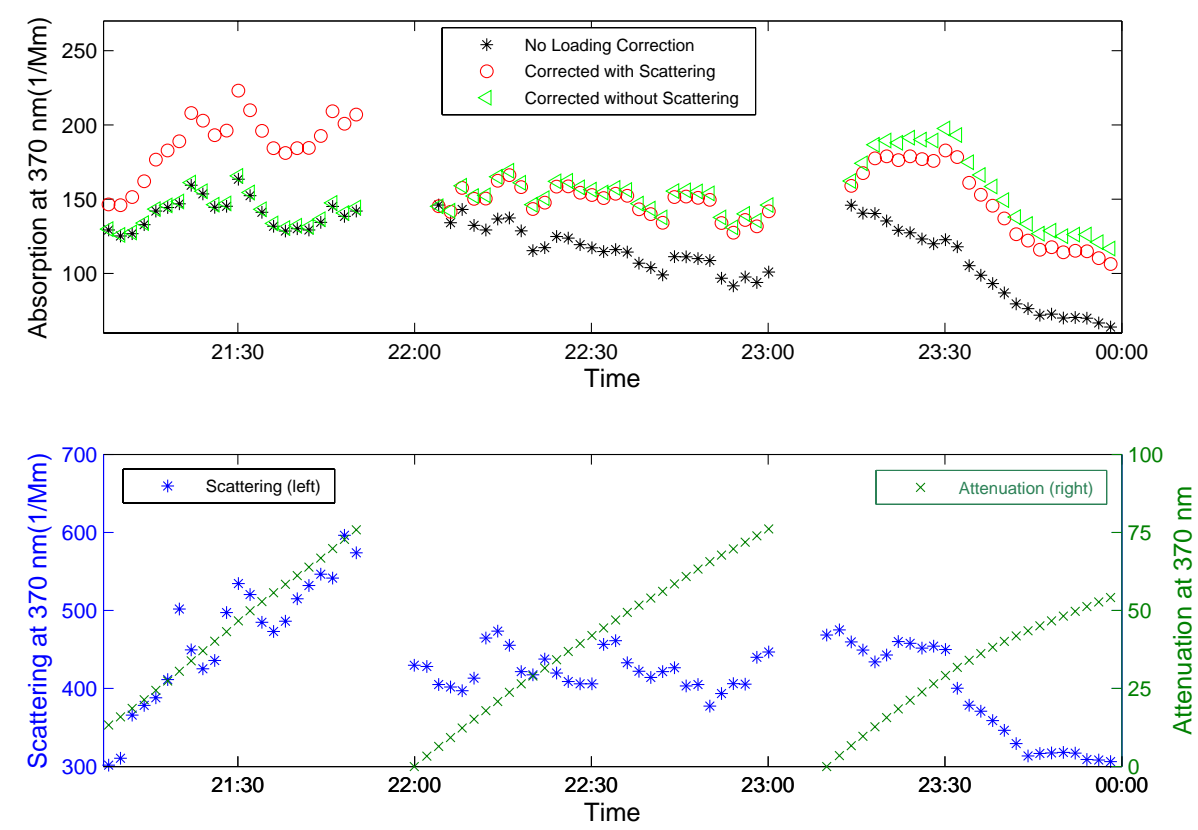

Fig. 1. Aethalometer loading correction: absorption coefficients not corrected, corrected with scattering, and corrected without scattering (top panel); scattering coefficient from the nephelometer and attenuation from the aethalometer (bottom panel). The aethalometer filter tape advances when attenuation at $370 \mathrm{~nm}$ exceeds 75 . During the filter advancement at $\sim 22: 00 \mathrm{UTC}$, the aerosol concentration dropped rapidly, as indicated by concurrent scattering; this is reflected in the aethalometer absorption corrected with scattering, but not in the absorption corrected without scattering, where absorption before and after the filter change were forced to be equal. The aerosol concentration was relatively steady during the filter advancement just after 23:00, so corrections with and without scattering led to similar results.

Uniform Deposit Impactor (MOUDI) during selected twelvehour intervals. The MOUDI was set to collect particles at a flow rate of $30 \mathrm{~L} / \mathrm{min}$ on nine successive impactor stages. Those nine stages consisted of aluminum substrates, while a backup quartz filter in the collected the smallest particles. The aerodynamic size-cuts were $18,10,6.2,3.1,1.8,1.0$, $0.56,0.30,0.17$, and $0.05 \mu \mathrm{m}$, where the first is a crude approximation for the inlet size, and the last is an arbitrary number for the backup filter. Particles collected on each stage were then analyzed by a similar Sunset Lab OCEC procedure, as batch samples. Because the aluminum substrate is not transparent to the OCEC laser, the split-point between OC and EC from the laser transmission could not be obtained directly for the first nine stages; instead only total carbon $(\mathrm{EC}+\mathrm{OC})$ was outputted. The final quartz filter is transparent to the laser; from that we determined the split-point between OC and EC as above and assigned it to the preceding aluminum stages, assuming that carbonaceous particles of different sizes evolve under the same temperatures. We also checked split-points obtained directly from the Sunset lab semi-continuous OCEC analyzer at concurrent times as the MOUDI; the semi-continuous instrument generally yielded comparable splits.

\subsection{Inorganic particulate measurements}

Every three hours, we collected particles on a $47 \mathrm{~mm}$ diameter Savilex Teflon filter at a flow rate of $\sim 20$ SLPM for the first two hours and $40 \mathrm{~min}$ (except the 0500 to 0640 and 1700 to 1840 samples that were over an hour and $40 \mathrm{~min}$ ). After drying and weighing for the gravimetric mass, filters were extracted with water and concentrations of sodium $\left(\mathrm{Na}^{+}\right)$, potassium $\left(\mathrm{K}^{+}\right)$, chloride $\left(\mathrm{Cl}^{-}\right)$, sulfate $\left(\mathrm{SO}_{4}^{2-}\right)$, nitrate $\left(\mathrm{NO}_{3}^{-}\right)$, oxalate $\left((\mathrm{COO})_{2}^{2-}\right)$, calcium $\left(\mathrm{Ca}^{2+}\right)$, magnesium $\left(\mathrm{Mg}^{2+}\right)$, and ammonium $\left(\mathrm{NH}_{4}^{+}\right)$were measured by ion chromatography. Analytical details can be found in Kline et al. (2004).

\subsection{Particle number measurement}

We measured the size-distributed particle number concentration with a TSI Aerodynamic Particle Sizer (APS) every $20 \mathrm{~s}$. The APS separates aerosols according to their aerodynamic (flow) diameters between $\sim 0.5$ and $\sim 20 \mu \mathrm{m}$ (Ananth and Wilson, 1988). However, the sizing and detecting efficiencies are relatively poor below $\sim 0.7 \mu \mathrm{m}$, while significant particle loss from the inlet to the detector limits its sampling efficiency for aerosols greater than $\sim 10 \mu$ min diameter. To account for irregular particle shapes and non-unity densities, we first applied an empirical Stokes correction according to the APS manual, and then converted aerodynamic di- 

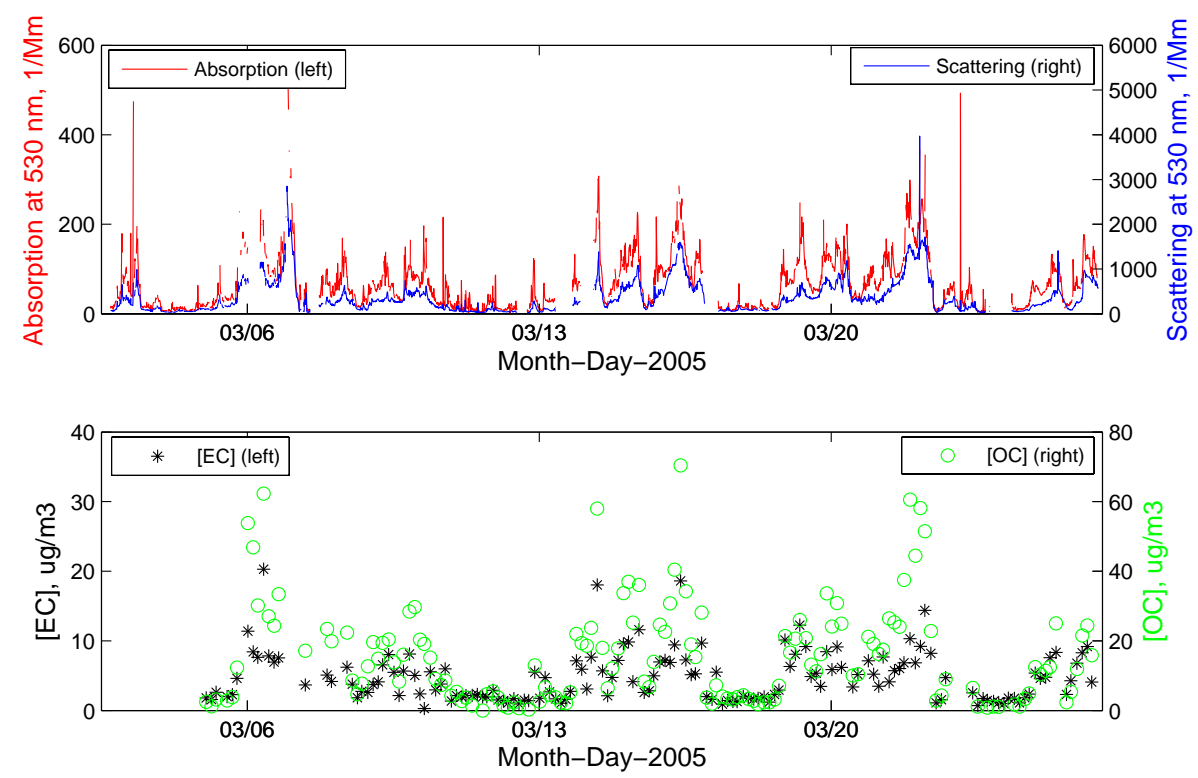

Fig. 2. Ten-minute averages of ambient absorption coefficients (1/Mm) from the aethalometer and scattering coefficients $(1 / \mathrm{Mm})$ from the nephelometer at $520 \mathrm{~nm}$ (top panel); filter-interval $(\sim 3 \mathrm{~h})$ averages of EC and OC concentrations $\left(\mu \mathrm{g} / \mathrm{m}^{3}\right)$ from the Sunset Lab semicontinuous OCEC analyzer (bottom panel). The correlation coefficient between EC and OC was about 0.9.

ameters to equivalent geometric diameters (as if the particles are spherical) by dividing by the square root of the effective density. Since aerosols sized by the APS are mostly coarse dust particles that tend to have a plate-like morphology and hence a large shape factor, we chose an effective density of $2.0 \mathrm{~g} \mathrm{~cm}^{-3}$ (as proposed by Reid et al., 2003), which is lower than the typical density of minerals $\left(\sim 2.6 \mathrm{~g} \mathrm{~cm}^{-3}\right)$. An irregular-shaped particle is accelerated faster in the APS flow than a sphere of the same mass due to the larger surface area, and hence appears to be smaller to the instrument. We therefore need to use an effective density that is lower than the actual density in the conversion from aerodynamic to equivalent geometric diameters. With the latter, size-distributed aerosol number concentrations can be simply converted to volume concentrations.

The total particle number concentration was monitored by a TSI Condensation Particle Counter 7610 (CPC), which has a lower cut-off diameter of $12 \sim 15 \mathrm{~nm}$.

\subsection{Other available measurements}

Basic meteorological measurements were made at a tower $\sim 75 \mathrm{~m}$ away from the IAP building every $10 \mathrm{~min}$ at five levels $(2,4,8,16$, and $32 \mathrm{~m}$ above ground). Our inlets on the roof of the IAP building corresponded to a height between 16 and $32 \mathrm{~m}$.

Russell Dickerson's group from the University of Maryland measured gas concentrations of carbon monoxide (CO), nitric oxide $(\mathrm{NO})$, reactive odd nitrogen $\left(\mathrm{NO}_{\mathrm{y}}\right)$, and sulfur dioxide $\left(\mathrm{SO}_{2}\right)$ on 10-min intervals.

\section{Results}

In general, atmospheric dynamics can account for most of the observed variability in aerosol concentrations. Correlation coefficients calculated between any pairs of gaseous and/or particulate species were almost always greater than 0.6. For species closely related in origin, such as between OC and EC, the correlation was close to 0.9. Figure 2 shows the time-series of aethalometer absorption coefficients and nephelometer scattering coefficients at $520 \mathrm{~nm}(10$-min averages, top panel) and EC and OC concentrations (3-h averages, bottom panel).

To examine aerosols in Xianghe over the course of an average day, we binned our measurements to the $24 \mathrm{~h}$ of a day (Fig. 3). We saw a bimodal distribution for most extensive variables, including absorption, scattering, and concentrations of OC and EC. The single scatter albedo was the lowest and the absorption Angstrom was the closest to one at times when extensive properties peaked, confirming that soot carbon was one of the principal aerosols emitted from morning and evening cooking and traffic emissions.

\subsection{Identification of end-member air masses}

During our three weeks of sampling in Xianghe, we encountered air dominated by fresh chimney plumes, other coal-burning emissions, and occasional biomass burning and dust aerosols, often at separate times. Based on chemical, optical, and particle size measurements, we identified periods when each type of air mass was prevalent. 

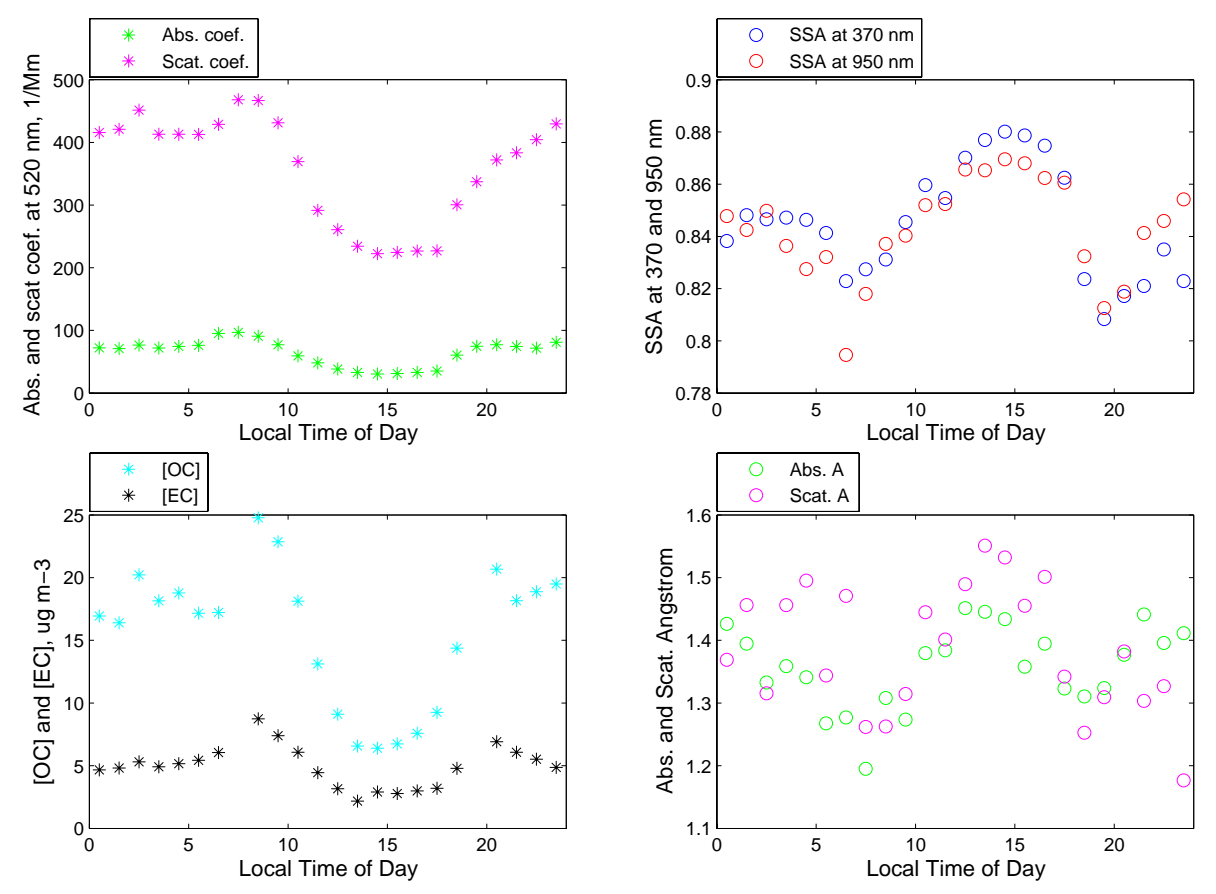

Fig. 3. Absorption and scattering at $520 \mathrm{~nm}$ (top left panel), single scatter albedo at 370 and $950 \mathrm{~nm}$ (top right panel), (OC) and (EC) (bottom left panel), and absorption and scattering Ångstrom exponents (bottom right panel) binned to the $24 \mathrm{~h}$ of a day. Extensive properties (left column) increased in morning and evening traffic, cooking hours, whereas intensive properties (right column) decreased, suggesting that a large fraction of those emissions was soot carbon.

Table 1. Identification criteria for end-member air masses.

\begin{tabular}{|c|c|c|}
\hline Air Mass Type & Identification Criteria & Exclusions \\
\hline Dust & $\begin{array}{l}\text { Coarse volume fraction }{ }^{\mathrm{a}} 1 \sigma \text { above median } \\
\text { fine scattering fraction }{ }^{\mathrm{c}} \text { at } 550 \mathrm{~nm} 1 \sigma \text { below median } \\
\mathrm{Ca} \text { CO ratio } 1 \sigma \text { above median }\end{array}$ & $\begin{array}{l}\text { Coarse number fraction }{ }^{\mathrm{b}} \text { below } 0.01 \\
\omega_{0} \text { at } 550 \mathrm{~nm} \text { below } 0.8\end{array}$ \\
\hline $\begin{array}{l}\text { Biomass Burning } \\
\text { Aerosols }\end{array}$ & $\begin{array}{l}\omega_{0} \text { at } 550 \mathrm{~nm} \text { above } 0.87 \text { within } 1 \mathrm{~h} \\
\text { of observed upwind agricultural fires }\end{array}$ & Times already identified as dust \\
\hline $\begin{array}{l}\text { Fresh chimney } \\
\text { Plumes }\end{array}$ & $\begin{array}{l}\text { NO:CO ratio } 1 \sigma \text { above median } \\
\text { Wind speed at } 32 \mathrm{~m} \sigma \text { below median }\end{array}$ & \\
\hline $\begin{array}{l}\text { Other coal } \\
\text { Pollution }\end{array}$ & $\mathrm{SO}_{2}: \mathrm{CO}$ ratio $2 \sigma$ above median & Times alreaady identified as fresh chimney plumes \\
\hline Background air & $\begin{array}{l}b_{s p} \text { at } 550 \mathrm{~nm} \text { less than } 50 \mathrm{Mm}- \\
\text { Wind speed at } 32 \mathrm{~m} \text { above } 8 \mathrm{~m} / \mathrm{s}\end{array}$ & Coarse volume fractiona above 0.94 \\
\hline
\end{tabular}

a The fraction of total particle volume due to supermicron particles, as inferred from the APS.

$\mathrm{b}$ The fraction of total number due to supermicron particles, as inferred from the APS and CPC.

${ }^{c}$ Fine Scattering Fraction: the fraction of total scattering due to submicron particles.

The identification criteria largely consist of intensive properties of the aerosols and do not depend on absolute concentrations (Table 1).
We normalize the concentration of trace gases and inorganics by that of carbon monoxide (CO) to minimize the influence of atmosphere dynamics and dilution (CO has a lifetime of months and should therefore be relatively wellmixed, Novelli et al., 1992). To identify end-members, we 
generally looked for multiple intensive properties to be one standard deviation away from the respective medians. The threshold of $1 \sigma$ is somewhat arbitrary, but in practice appears to be strict enough to capture distinctions in air masses and yet lenient enough so that a reasonable sample size remains. As shown in the dust example below, we have more confidence in our air mass identification when multiple proxies converge.

The identification of dust was based on particle size and composition. Calcium is one of the major components of these coarse particles (Arimoto et al., 2004). High Ca:CO ratios corresponded nicely with low fine scattering fraction (FSF, or the fraction of total scattering due to submicron particles from the nephelometer), as shown in Fig. 4. Low coarse number fraction (total supermicron particle number from the APS divided by the CPC count) and $\omega_{0}$ were excluded since both imply a combustion source for the aerosols.

A widely used proxy for biomass burning aerosols is soluble potassium. Yet our potassium peaks did not correspond to any observed biomass burning events, possibly because sporadic agricultural fires reached our site for usually only a few minutes at a time. Those relatively weak and shortlived signals could easily be obscured in the 3-hour filter samples. Instead, we looked for high single scatter albedo at $550 \mathrm{~nm}$ around occasions when we observed field fires upwind, which tended to give out whitish smoke and raise $\omega_{0}$ when reaching our inlets. Previous studies also suggested that aerosols from biomass burning are characterized by relatively high single scatter albedo in the mid-visible (Kaufmann et al., 1992; Penner et al., 2001). Since mineral dust could also have high $\omega_{0}$ at $550 \mathrm{~nm}$, periods already classified as dust were not double-counted as biomass burning.

Rapidly varying chimney plumes from nearby sources were of interest because fresh emissions from these industrial boilers (likely burning diesel oil or coal) are expected to resemble "pure" soot the most. While NO and CO are both byproducts of fossil fuel combustion, NO has a very short life time in the atmosphere (hours) and its concentration is expected to fall off more quickly away from the source of combustion than the more stable CO. Classification based on this criterion was consistent with our visual and olfactory observations of chimney plumes, especially at low wind speeds.

In addition to fresh chimney plumes, there were very often long-lasting periods with constantly high levels of coal burning pollution, which likely originated from residential heating and cooking and distant smokestacks. Under stagnant conditions, these highly absorbing pollutants accumulated to very high levels. We looked for a very high $\mathrm{SO}_{2}: \mathrm{CO}_{2}$ ratio because $\mathrm{SO}_{2}$ is one of the principal gases emitted from coal burning and has a much shorter lifetime than CO. Coalderived emissions from this project generally had a relatively low $\omega_{0}$ and an abundance of large particles, though neither was used as a criterion. To identify background air, we decided to simply look for times that were low in scattering instead of using intensive properties. A high wind speed

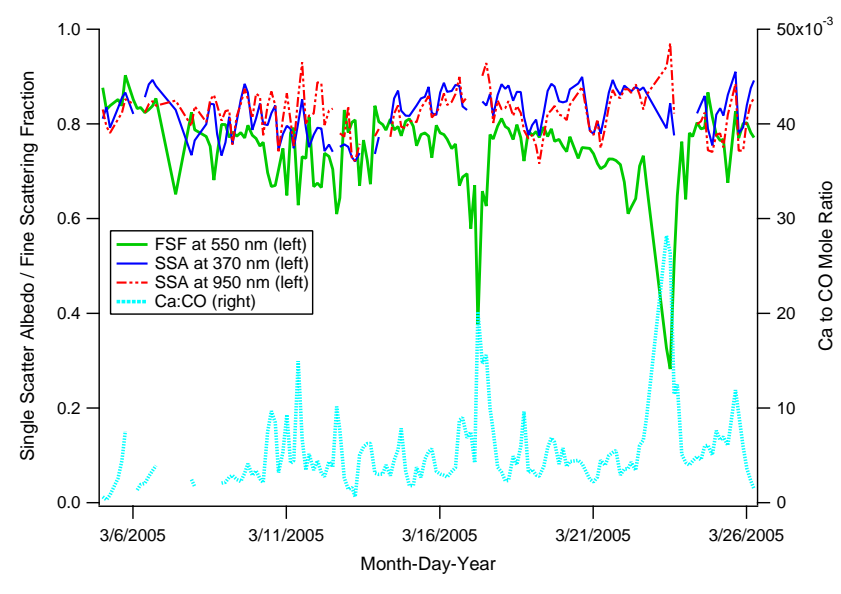

Fig. 4. Identification of dust by size (low fine scattering fraction, FSF) and soluble calcium (high Ca:CO ratio). Notice that the single scatter albedo decreased at $370 \mathrm{~nm}$ and increased at $950 \mathrm{~nm}$ during dust events (e.g., 23 March) as a result of the high absorption Ångstrom exponent of dust.

was chosen because strong winds often dissipated local pollution. We discarded times when the coarse volume fraction (fraction of total aerosol volume due to supermicron particles from the APS) was greater than 0.94 as a way to avoid double counting with mineral dust, which had already been categorized.

\subsection{Optical characteristics of end-member air masses}

The means and standard deviations (in parenthesis when appropriate) of the single scatter albedo for the entire project and also for end-member air masses are summarized in Table 2. Total absorption from the aethalometer and scattering from the nephelometer were used in the calculations in $2 a$, whereas absorption from the PSAP and scattering from the nephelometer were separated into fine and coarse modes in $2 \mathrm{~b}$. The submicron and supermicron $\omega_{0}$ averaged to 0.82 and 0.87 at $550 \mathrm{~nm}$, bracketing that of total aerosols. As expected, submicron $\omega_{0}$ was lower than supermicron $\omega_{0}$ because most of the absorption was due to fine mode carbonaceous aerosols. From uncertainties in the nephelometer scattering ( $\sim 7 \%$, mostly due to the truncation correction) and in the aethalometer absorption (19 26\% from 370 to $950 \mathrm{~nm}$, mostly due to the multiple scattering correction), we estimated the uncertainties of the single scatter albedo to be about 0.03 . This uncertainty is relatively consistent and systematic at all wavelengths, so we have more confidence in the spectral shapes than their absolute magnitudes.

Figure 5 shows the groupings of absorption and scattering Ångstrom exponents for the identified end-member air masses; these results are also tabulated in Table 3. The wavelength-dependence in absorption was calculated over the entire aethalometer wavelength range and also over the visible spectrum only, leading to almost identical results. The 
Table 2a. Single scatter albedo calculated from aethalometer absorption and nephelometer scattering.

\begin{tabular}{lccccccc}
\hline \multicolumn{7}{c}{ Single Scatter Albedo, Mean(Std) } \\
\hline Project mean & $82(0.06)$ & $83(0.05)$ & $83(0.05)$ & $83(0.05)$ & $82(0.06)$ & $82(0.06)$ & $82(0.06)$ \\
Dust & $84(0.03)$ & $87(0.03)$ & $89(0.03)$ & $90(0.03)$ & $91(0.04)$ & $93(0.05)$ & $93(0.06)$ \\
Biomass burning & $0.88(0.01)$ & $0.88(0.01)$ & $0.89(0.01)$ & $0.89(0.01)$ & $0.88(0.01)$ & $0.88(0.02)$ & $0.88(0.02)$ \\
Fresh Plume & $0.83(0.04)$ & $0.83(0.04)$ & $0.83(0.04)$ & $0.82(0.04)$ & $0.82(0.04)$ & $0.81(0.04)$ & $0.81(0.04)$ \\
Coal burning & $0.78(0.05)$ & $0.80(0.05)$ & $0.80(0.04)$ & $0.80(0.05)$ & $0.80(0.05)$ & $0.80(0.05)$ & $0.80(0.05)$ \\
Background & $0.83(0.05)$ & $0.84(0.05)$ & $0.84(0.05)$ & $0.84(0.05)$ & $0.83(0.05)$ & $0.83(0.06)$ & $0.82(0.06)$ \\
\hline
\end{tabular}

Table 2b. Single scatter albedo for total, submicron, and supermicron Aerosols.

\begin{tabular}{lccc}
\hline & \multicolumn{3}{c}{ Single Scatter Albedo at 550 $\mathrm{nm}^{\mathrm{a}}$, Mean (Std) } \\
& Total & Submicron & Supermicron \\
\hline Project mean & $0.84(0.05)$ & $0.82(0.05)$ & $0.87(0.08)$ \\
Dust & $0.90(0.04)$ & $0.86(0.05)$ & $0.94(0.03)$ \\
Biomass burning & $0.89(0.01)$ & $0.87(0.01)$ & $0.91(0.02)$ \\
Fresh plume & $0.83(0.04)$ & $0.79(0.03)$ & $0.86(0.05)$ \\
Coal pollution & $0.80(0.05)$ & $0.79(0.04)$ & $0.87(0.06)$ \\
Background air & $0.84(0.05)$ & $0.84(0.04)$ & $0.88(0.08)$ \\
\hline
\end{tabular}

a Absortption from the PSAP

wavelength-dependence in scattering was calculated over the more limited nephelometer wavelengths. Both absorption and scattering Ångstrom exponents averaged to $\sim 1.5$. The scattering Angstrom is usually inversely correlated with particle size, while a high absorption Ångstrom exponent implies the presence of light absorbing aerosols other than BC, such as dust and brown carbon.

At $550 \mathrm{~nm}$, the fine absorption fraction (the fraction of total absorption due to submicron particles from the PSAP) and fine scattering fraction averaged to 0.83 and 0.76 , respectively (Table 4). These two fractions are proxies for the relative contributions to total absorption and scattering from combustion-derived aerosols and dust particles.

\subsubsection{Dust}

The observed single scatter albedo was at its highest in the entire project during dust events at $0.90(550 \mathrm{~nm})$ and it increased from the UV to the IR. During EAST-AIRE, $\omega_{0}$ was much lower than the 0.97 seen during ACE-Asia (Anderson et al., 2003). One possible explanation is that the Xianghe dust were accompanied by light absorbing carbon (from interactions in the coal boiler and atmosphere, or from resuspension of soot deposited on the ground), whereas the free tropospheric dust observed during ACE-Asia did not have much contact with urban pollutants. Submicron and supermicron $\omega_{0}$ at dust-dominated times during EAST-AIRE were 0.86 and 0.94 at $550 \mathrm{~nm}$, both higher than their respective project means. The fine absorption and scattering fractions were 0.69 and 0.46 at these times, both much lower than project means, indicating the presence of more coarse particles. If only looking at total optical properties at these times (Fig. 5), we see a relatively large absorption Ångstrom exponent of 1.89 , which is not quite up to previously reported values of that of dust only $(\AA \approx 3)$, presumably due to the ever-present $\mathrm{BC}$ that follows a lower wavelength-dependence in absorption as a result of the small particle size and constant imaginary component of the refractive index in the visible spectrum. The low wavelength-dependence in scattering on average $(\AA=0.59)$ is characteristic of coarse particles that scatter in the geometric regime. The large variation in the scattering Ångstrom exponent is likely caused by the different mineralogy, size distributions, or coatings of dust.

\subsubsection{Biomass burning aerosols}

Compared to the respective project averages, biomass burning aerosols had similar wavelength-dependences in absorption and scattering; slightly lower FAF and FSF values suggest somewhat more large particles. The short durations and weak signals of this air mass, however, limit our ability to interpret its optical properties.

\subsubsection{Fresh chimney plumes}

The single scatter albedo was much lower in fresh chimney plumes. Overall, $\omega_{0}$ was 0.83 at $550 \mathrm{~nm}$, while submicron and supermicron $\omega_{0}$ were 0.79 and 0.86 , respectively. The wavelength-dependence in total absorption reached its project minimum in chimney plumes at $\AA=1.35$ (Fig. 5), im- 
Table 3. Ångstrom exponents of absorption (over the entire aethalometer wavelengths and also the visible spectrum only) and scattering (over the nephelometer wavelengths).

\begin{tabular}{lccc}
\hline & \multicolumn{3}{c}{ Ångstrom Exponents, Mean (Std) } \\
& \multicolumn{2}{c}{ Absorption } & Scattering \\
& $370 \sim 950 \mathrm{~nm}$ & $470 \sim 660 \mathrm{~nm}$ & $450 \sim 700 \mathrm{~nm}$ \\
\hline Project mean & $1.46(0.27)$ & $1.47(0.38)$ & $1.47(0.25)$ \\
Dust & $1.82(0.90)$ & $1.89(1.63)$ & $0.59(0.41)$ \\
Biomass burning & $1.49(0.08)$ & $1.53(0.10)$ & $1.52(0.18)$ \\
Fresh plume & $1.35(0.10)$ & $1.35(0.12)$ & $1.49(0.11)$ \\
Coal pollution & $1.46(0.15)$ & $1.47(0.17)$ & $1.39(0.20)$ \\
Background & $1.50(0.22)$ & $1.55(0.26)$ & $1.58(0.18)$ \\
\hline
\end{tabular}

Table 4. Fine absorption fraction and fine scattering fraction.

\begin{tabular}{lcccc}
\hline & Fine Absorption Fraction ${ }^{\mathrm{a}}$ & \multicolumn{3}{c}{ Fine Scattering Fraction $^{\mathrm{b}}$} \\
& $550 \mathrm{~nm}$ & $450 \mathrm{~nm}$ & $550 \mathrm{~nm}$ & $700 \mathrm{~nm}$ \\
\hline Project mean & $0.83(0.10)$ & $0.80(0.09)$ & $0.76(0.10)$ & $0.69(0.11)$ \\
Dust & $0.69(0.18)$ & $0.53(0.18)$ & $0.46(0.17)$ & $0.36(0.16)$ \\
Biomass burning & $0.80(0.06)$ & $0.79(0.05)$ & $0.73(0.05)$ & $0.65(0.06)$ \\
Fresh plume & $0.85(0.12)$ & $0.82(0.10)$ & $0.79(0.10)$ & $0.73(0.11)$ \\
Coal pollution & $0.85(0.08)$ & $0.82(0.08)$ & $0.77(0.08)$ & $0.70(0.08)$ \\
\hline
\end{tabular}

${ }^{\text {a }}$ FAF - the fraction of absorption due to fine mode particles, Mean (Std)

${ }^{b}$ FSF - the fraction of scatterng due to fine mode particles, Mean (Std)

plying that these aerosols were the most similar to fresh soot. The fine absorption and scattering fractions were 0.85 and 0.79 , respectively; both were higher than the project means, confirming a high fraction of fine absorbing particles. However, this absorption Ångstrom exponent is still 30\% higher than what is expected for soot only (unity); this indicates the ubiquitous presence of other light absorbing aerosols near Xianghe.

\subsubsection{Other coal pollution}

Residential combustion of coal briquettes seemed to result in emissions of large particles, presumably either from the clay binder or directly from the coal, in addition to soot. The lowest $\omega_{0}$ during the entire project was found in coalderived aerosols, with an average of 0.80 at $550 \mathrm{~nm}$. Unlike in fresh chimney plumes where $\omega_{0}$ decreased with wavelength, $\omega_{0}$ for these coal-derived aerosols showed no obvious wavelength-dependence. Compared to chimney plumes, the higher absorption Ångstrom (1.47) and lower scattering Ångstrom (1.39) in these coal-derived aerosols indicate more large particles that are less similar to soot (again, Fig. 5).

\subsubsection{Background air}

The background air, which was identified by low scattering, closely resembled the average atmosphere in Xianghe in terms of the single scatter albedo. The low $\omega_{0}$ in Northern China even when the atmosphere was relatively clean underlines the importance of coal burning emissions.

\section{Discussion}

As a first order approximation for the EC mass absorption efficiency, we can normalize total absorption by the mass concentration of EC. The resultant "apparent" EC MAE (project mean of $11.3 \mathrm{~m}^{2} / \mathrm{g}$ at $550 \mathrm{~nm}$ ), however, would be $\sim 40 \%$ higher than that recommended by Bond and Bergstrom (2006) for fresh soot carbon at this wavelength $\left(7.5 \pm 1.2 \mathrm{~m}^{2} / \mathrm{g}\right)$. This suggests that total light absorption cannot be explained by soot carbon alone, which is also evident in the relatively strong wavelength-dependence $(\AA \approx 1.5)$. Rather, other light absorbing materials were present also and absorbed a lot more at shorter wavelengths than at longer wavelengths. Brown carbon and dust are two potentially significant light absorbers that are known to have high absorption Ångstrom exponents in the visible spectrum. It is worth mentioning here that if brown carbon causes an artifact in thermal-optical methods, as suggested by Subramanian et al. (2007), some of the EC values might be erroneously low, leading to high "apparent" EC MAE.

We also considered the effect of coating of soot by transparent condensates. Recent modeling studies (Fuller et 


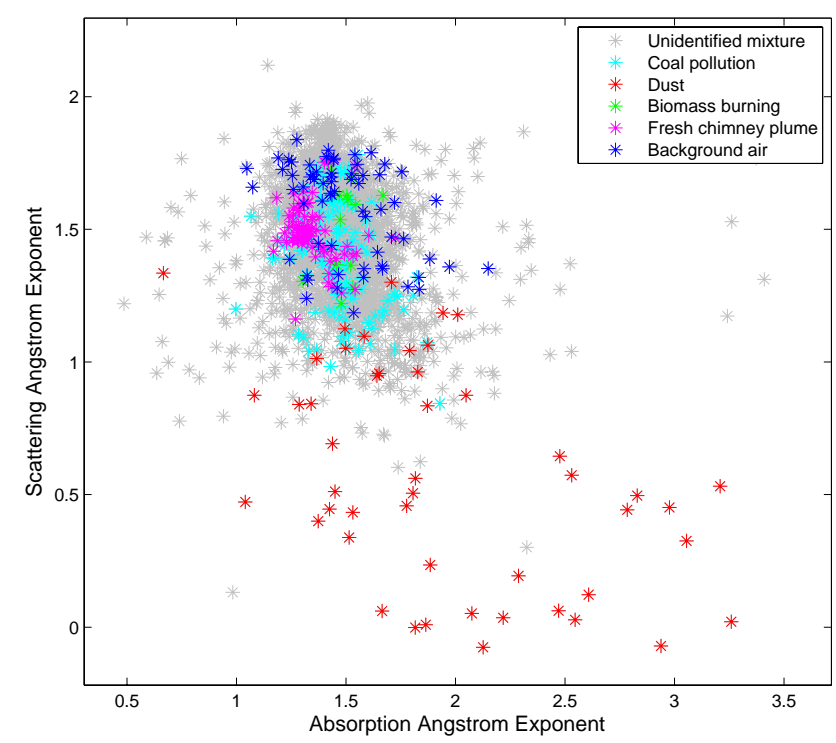

Fig. 5. Grouping of air masses by absorption and scattering Ångstrom exponents. Dust generally had a low scattering $\AA$ (close to zero) due to the large particle size, while its absorption $\AA$ was high but variable. Fresh chimney plumes were characterized by a near-unity absorption $\AA$, which is expected for soot carbon. In comparison, coal pollution aerosols were much more variable in optical characteristics, likely due to formation of brown carbon and clay in addition to soot carbon.

al., 1999; Schnaiter et al., 2003; Bond et al., 2006) suggested that external mixing of $\mathrm{BC}$ with weakly-absorbing materials does not significantly increase absorption, but a complete encapsulation of a BC core by condensates could result in an absorption enhancement of about 30 50\%. While such an increase would be large enough to explain our high "apparent" EC MAE, we have no reason to attribute the high absorption Angstrom exponent of $\sim 1.5$ to this encapsulation effect. Modeling and laboratory studies have not indicated any consistent increase in the wavelengthdependence of $\mathrm{BC}$ absorption due to coating. On the contrary, Schnaiter et al. (2005) reported a slightly decreasing absorption Ångstrom exponent with increasing internal mixing of black carbon with secondary organic aerosols.

Soot, being in the Rayleigh regime, is expected to have a greater wavelength-dependence in scattering than in absorption. Thus, its single scatter albedo should decrease with increasing wavelength. Both dust and brown carbon, however, can have greater wavelength-dependences in absorption than in scattering. The single scatter albedo for these two types of aerosols should therefore increase with wavelength. During EAST-AIRE, the project average single scatter albedo was low in IR and UV and peaked in the mid-visible, again suggesting a mixture of $\mathrm{BC}$ with other absorbing aerosols.

\subsection{BC absorption}

Accepting that BC follows the inverse-wavelength relationship from 370 to $950 \mathrm{~nm}$, we can approximate BC absorption at any wavelength within this spectrum if we know its absorption at one wavelength. We can further assume that BC is the only significant light absorber at $950 \mathrm{~nm}$, since both brown carbon and dust absorb weakly in the near-IR (inferred from Andreae and Gelencser, 2006; Sokolik and Toon, 1999, respectively). Then we can use the absorption Ångstrom exponent of one to extrapolate $\mathrm{BC}$ absorption from $950 \mathrm{~nm}$ to shorter wavelengths. A similar argument was used in Clarke et al. (2007), but based on negligible non-soot absorption at $670 \mathrm{~nm}$.

We define the difference between total absorption and extrapolated BC absorption as residual absorption. The residual absorption was zero at $950 \mathrm{~nm}$ by definition and increased to over $30 \%$ of total absorption at $370 \mathrm{~nm}$. In the mid-visible, the contribution to total absorption by aerosols other than $\mathrm{BC}$ was $\sim 15 \%$. The residual absorption had an absorption Ångstrom exponent of $\sim 3.5$ in the visible spectrum, which is close to those of brown carbon and dust. The very high correlation coefficient between residual absorption and OC concentration (0.95) suggested that most of the residual absorption was due to brown carbon.

We can now normalize the extrapolated $\mathrm{BC}$ absorption to the elemental carbon concentration to obtain the EC mass absorption efficiency. The resultant "true" EC MAE (project mean of $9.5 \mathrm{~m}^{2} / \mathrm{g}$ at $550 \mathrm{~nm}$ ) represents a $\sim 20 \%$ reduction from the "apparent" EC MAE, and is much closer to the recommendation by Bond and Bergstrom (2006) and well within the range of enhancements likely to be caused by encapsulation. Alternatively, the remaining discrepancy between our EC MAE and that recommended by Bond and Bergstrom may be accounted for if we had used an absorption Ångstrom of less than 0.6 for the BC absorption extrapolation. However, the ambient absorption Ångstrom was very rarely below one during EAST-AIRE. Furthermore, an absorption Ångstrom of unity is most consistent with the Rayleigh scattering theory. Varying $\AA$ by a reasonable range of \pm 0.2 leads to a $\sim 10 \%$ change in the extrapolated $\mathrm{BC}$ absorption in either direction, which doesn't significantly affect the rest of our interpretations.

\subsection{Dust absorption}

While the absorption of mineral dust depends on its content of ferric oxides (Sokolik and Toon, 1999; Alfaro et al., 2004), in urban environments, volatile materials such as OC, sulfates, and nitrates from combustion can be adsorbed onto dust surfaces (Zhang and Carmichael, 1999; Falkovich et al., 2004; Putaud et al., 2004), possibly modifying the dust optical properties. From size-segregated mass concentrations sampled by the MOUDI, we see that unlike pollution times when most mass was concentrated in the fine 

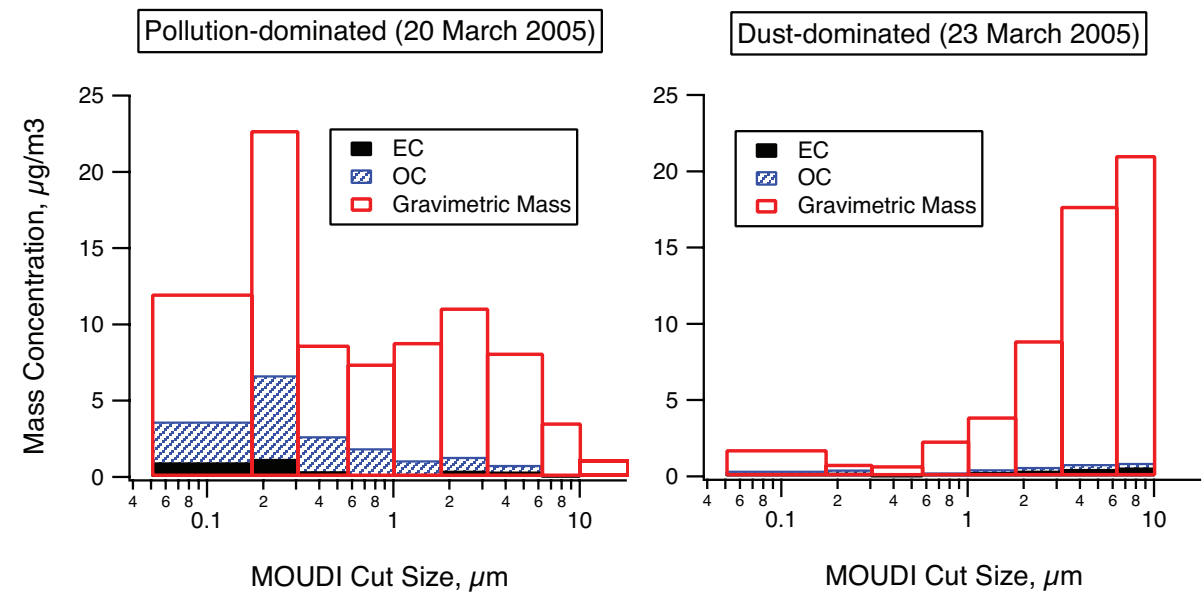

Fig. 6. Size-segregated mass concentrations from the MOUDI. Most carbonaceous mass (OC and EC) was in the fine mode during pollutiondominated times (left panel). However, during dust-dominated times (right panel), there was a lot more carbon $(\sim 50 \%)$ present in the coarse mode, possibly adsorbed onto surfaces of dust particles.

mode, dust events were characterized by a high fraction of mass, including that of carbonaceous particles, in the coarse mode (Fig. 6). Dust particles sampled in polluted places like Xianghe, therefore, should not be considered pure mineral aerosols. During EAST-AIRE, dust events usually coincided with high winds which re-suspended local coarse particles; it is unclear whether long-distance transport of desert aerosols was important. As mentioned before, some of these coarse particles might be generated during the combustion of coal (briquettes). This scenario is more plausible in bringing light absorbing carbon into the coarse mode than natural coagulation.

Since we could not directly measure the mass concentration and light absorption of dust, we estimated these two quantities from the size-distributed number concentrations from the APS using Mie scattering theory. Knowing that pollution aerosols tend to dominate in the fine mode, we only used the supermicron portion of the size-distributed number concentrations for this Mie calculation. Even though the dust number distribution might have a tail in the fine mode, (which we could not constrain due to a lack of size-distributed chemical concentration sampling and particle number count below $\sim 0.7 \mu \mathrm{m}$ ) mass, scattering, and absorption due to dust are all dominated by coarse particles, as shown by Clarke et al. (2004) in their measurements during ACE-Asia. This Mie calculation also required a reasonable refractive index for dust aerosols. However, the imaginary component of the refractive index of dust varies over an order of magnitude among literature values, from $0.0006 \mathrm{i}$ to $0.0015 \mathrm{i}$ to $0.008 \mathrm{i}$ in the mid-visible (Clarke et al., 2004; Haywood et al., 2003; World Meteorological Organization, 1986).

To determine the refractive index of dust appropriate for Xianghe, we first focused on identified end-member dust events during EAST-AIRE and assumed that absorption due to brown carbon was negligible at those times (i.e. residual absorption, or the difference between total absorption and $\mathrm{BC}$ absorption, was solely due to dust). This assumption was supported by the fact that correlation between coarse volume and residual absorption at $370 \mathrm{~nm}$ was $\sim 0.9$ during dust events, much higher than $\sim 0.5$ for the project average. At each aethalometer wavelength, we varied the imaginary component of the refractive index from $0 \mathrm{i}$ to $0.01 \mathrm{i}$, while keeping the real component constant at 1.53 - a value commonly used to model dust (Sokolik and Toon, 1999; Haywood et al., 2003; Clarke et al., 2004). Absorption predicted by Mie scattering theory was then summed over all sizebins to generate total absorption. The fitting was deemed optimal when the square of the difference between residual absorption and Mie-predicted absorption was the smallest on average at those end-member dusty periods. For 370 , $470,520,590,660,880$, and $950 \mathrm{~nm}$, our least-square-fit method yielded an imaginary component of $0.0056 \mathrm{i}, 0.0033 \mathrm{i}$, $0.0026 \mathrm{i}, 0.0019 \mathrm{i}, 0.001 \mathrm{i}, 0.0001 \mathrm{i}$, and $0 \mathrm{i}$, respectively. By interpolation, a refractive index of $1.53-0.0023 \mathrm{i}$ at $550 \mathrm{~nm}$ was obtained, which is in the range of previously published results. Now for the entire EAST-AIRE project, using Mie theory, we applied this set of empirically-derived refractive indices to all supermicron particle number concentrations to obtain a complete time-series of dust absorption. This calculation assumes that all coarse particles during EAST-AIRE had the same optical properties, whether during dust events or not, which might not be valid if some of the large aerosols were combustion-origin. Based on this estimation, absorption due to dust was usually quite minor in Xianghe except during dust events.

Considering again only the supermicron particles from the APS distributed by equivalent geometric diameters, we 
Table 5. Mass absorption efficiencies and absorption Ångstrom exponents of black carbon, dust, and brown carbon.

\begin{tabular}{lccccccc}
\hline & \multicolumn{3}{c}{ Mass Absorption Efficiency Project Mean $\left[\mathrm{m}^{2} / \mathrm{g}\right]$} & \multicolumn{2}{c}{ Absorption $\AA$} \\
& $370 \mathrm{~nm}$ & $470 \mathrm{~nm}$ & $520 \mathrm{~nm}$ & $590 \mathrm{~nm}$ & $660 \mathrm{~nm}$ & $880 \mathrm{~nm}$ & $470 \sim 660 \mathrm{~nm}$ \\
\hline Total Absorption & 21.4 & 14.6 & 12.3 & 10.2 & 8.9 & 5.9 & 1.47 \\
BC $^{\mathrm{a}}$ & 14.1 & 11.1 & 10.0 & 8.8 & 7.9 & 5.9 & 1.00 \\
Dust $^{\mathrm{b}}$ & 0.087 & 0.050 & 0.037 & 0.027 & 0.013 & 0.001 & 3.80 \\
Brown Carbon $^{\mathrm{c}}$ & 2.2 & 1.01 & 0.63 & 0.37 & 0.32 & 0.02 & 3.50 \\
\hline
\end{tabular}

a Absorption normalized by (EC)

b Absorption normalized by estimated dust concentration

c Absorption normalized by (OC)

calculated the mass concentration of dust from volume using a constant density of $2.6 \mathrm{~g} / \mathrm{cm}^{3}$. We could also estimate the mass concentration of dust from soluble calcium, as previous experiments suggested that water-soluble calcium makes up $\sim 5-8 \%$ of total dust mass (Arimoto et al., 2004); this latter approach yielded similar results. The mean dust MAE was determined to be $0.03 \mathrm{~m}^{2} / \mathrm{g}$ at $550 \mathrm{~nm}$, over two orders of magnitude less than that of black carbon. Published results of the absorption Ångstrom exponent of dust are over the visible spectrum only, likely because a power law fit might not be suitable for dust absorption from 370 to $950 \mathrm{~nm}$ due to its particular spectral shape, as seen in modeled spectra from Sokolik and Toon (1999). We calculated our wavelength-dependence in dust absorption from 470 to $660 \mathrm{~nm}$ (Table 5), resulting in an average of 3.8. A large range in the wavelength-dependence was observed, which could be due to a number of modification processes that these dust aerosols might have undergone.

\subsection{Brown carbon absorption}

We derived our absorption due to brown carbon by subtracting $\mathrm{BC}$ and dust absorption from total absorption at all wavelengths, assuming that nothing besides black carbon, brown carbon, and dust had any significant absorption between 370 and $950 \mathrm{~nm}$ during EAST-AIRE. For the mass concentration of brown carbon, we decided to simply use the total particulate organic carbon concentration measured by the Sunset lab OCEC Semi-continuous analyzer. Knowing that a large fraction of organic carbon is non-absorbing, dividing brown carbon absorption by an upper-limit concentration will give us a lower-limit mass absorption efficiency. The real mass absorption efficiency for brown carbon will surely be higher than the values presented here. The advantage of normalizing brown carbon absorption to organic carbon, however, is that the mass concentration of organic carbon can be measured by the same technique in different labs (Schauer et al., 2003) and is thus more reproducible than that of brown carbon.

The mean brown carbon MAE was determined to be $0.5 \mathrm{~m}^{2} / \mathrm{g}$ at $550 \mathrm{~nm}$, less than one tenth of the EC MAE at the same wavelength. The average absorption Ångstrom ex- ponent of brown carbon during EAST-AIRE was 3.5 over the visible spectrum, which is higher than what were commonly reported for biomass burning aerosols ( $\AA \approx 2$; Clarke et al., 2006; Kirchstetter and Novakov, 2004; Kline, J., 2004). However, when contribution from BC was removed from total absorption, those authors found similarly high absorption Ångstrom exponents.

Table 5 summarizes the project mean mass absorption efficiencies $\left(\mathrm{m}^{2} / \mathrm{g}\right)$ and absorption Ångstrom exponents of black carbon, brown carbon, and dust. Via propagation of errors, the uncertainty in the EC concentration from the OCEC analyzer was estimated to be $\sim 17 \%$ (Kline, 2004). Combined with the propagated uncertainties in the aethalometer absorption of 19 26\%, the EC mass absorption efficiency should have uncertainties of 26 31\% (from 370 to $950 \mathrm{~nm}$ ). Figure 7 shows the average contribution to total light absorption by black carbon, brown carbon, and dust from 370 to $950 \mathrm{~nm}$. Black carbon was predictably the most important light-absorbing aerosol; though its importance to total absorption decreased towards shorter wavelengths, where brown carbon and dust became more significant. Brown carbon on average could account for $\sim 30 \%$ of total absorption at $370 \mathrm{~nm}$. Even at mid-visible wavelengths, it still contributed more than $10 \%$, underlining the optical importance of absorbing organic carbon in environments dominated by coal burning. The absorption due to dust was generally small (less than $5 \%$ at $370 \mathrm{~nm}$ ), though its contribution to total absorption can be similar to that from BC during dust events.

\section{Conclusions}

A variety of in situ optical and chemical measurements were made on aerosols near Xianghe, China during the EASTAIRE campaign. Based on previously published methods, a correction scheme incorporating concurrent scattering was developed to address the loading artifact of the aethalometer. The single scatter albedo from 370 to $950 \mathrm{~nm}$ was directly calculated from aethalometer absorption and nephelometer scattering. In general, aerosols in Xianghe were highly absorbing, as demonstrated by the low $\omega_{0}$ at all wave- 

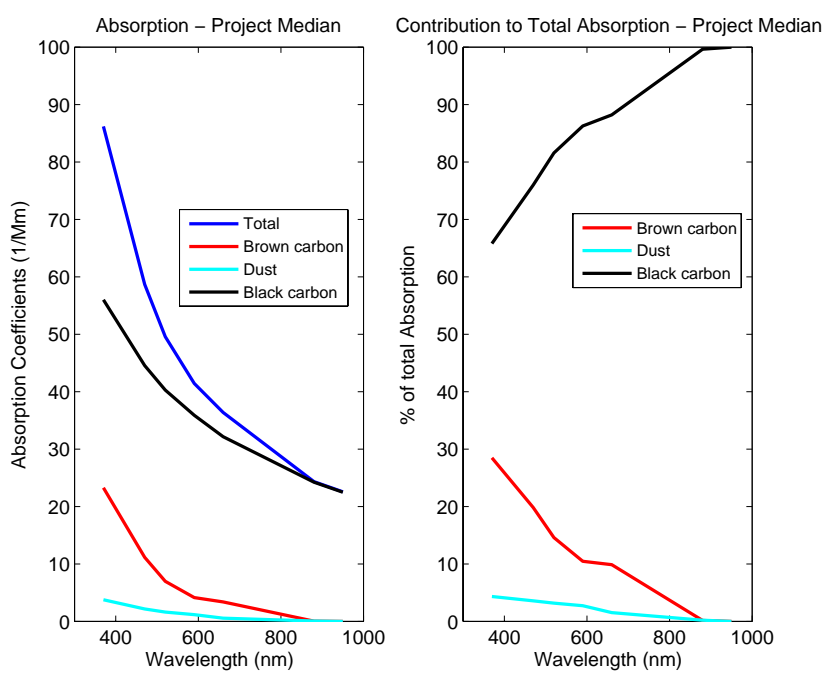

Fig. 7. Apportioning of total light absorption to black carbon, brown carbon, and dust: project medians of their absolute absorption (left panel) and relative contributions (right panel). BC's contribution to total absorption decreased towards the UV, where brown carbon and dust became more important. For this coal-dominated environment, brown carbon could account for $\sim 30 \%$ of total light absorption in the UV, and over $10 \%$ at mid-visible wavelengths.

lengths (project mean and standard deviation of $0.84 \pm 0.05$ at $550 \mathrm{~nm})$. We also quantified absorption and scattering in the coarse and fine modes separately at $550 \mathrm{~nm}$; the submicron $\omega_{0}$ was found to be lower than the supermicron $\omega_{0}$. On average, both absorption and scattering Ångstrom exponents were close to 1.5 , suggesting the presence of large, absorbing particles.

We identified five end-member air mass types that might be characteristic of Northern China, which are dust, biomass burning aerosols, fresh (industrial) chimney plumes, other (residential and commercial) coal-derived aerosols, and the background air. Optical properties varied significantly among these air masses as a result of their different chemical compositions. In the mid-visible, dust and biomass burning aerosols had the highest single scatter albedo among identified air masses. Dust, as characterized by high calcium and coarse scattering, had the lowest scattering Ångstrom exponent due to the large particle size and a high absorption Ångstrom exponent due to the presence of ferric oxides. During dust events, a higher percentage of the carbonaceous mass was found in the coarse mode than during pollutiondominated times, suggesting a possible surface adsorption mechanism of light absorbing carbon onto dust particles. Biomass burning and coal burning aerosols both showed high absorption Ångstrom exponents, likely because brown carbon was also produced. Fresh chimney plumes contained aerosols most resembling diesel soot (absorption $\AA$ closest to one).

We found that normalizing total absorption to the mass concentration of elemental carbon yielded an unrealistically high EC mass absorption efficiency, indicating that light absorbers other than soot were present. We were able to attribute total light absorption to black carbon, brown carbon, and dust from 370 to $950 \mathrm{~nm}$, resulting in mass absorption efficiencies of $9.5,0.5$, and $0.03 \mathrm{~m}^{2} / \mathrm{g}$ at $550 \mathrm{~nm}$, respectively. The black carbon MAE might have been enhanced due to the coating effect. The brown carbon MAE should be viewed as a lower-limit since we normalized its absorption to the concentration of OC. The dust MAE represented those of local coarse particles that had interacted with pollution rather than pure desert aerosols. The contribution to total absorption from $\mathrm{BC}$ decreased towards the $\mathrm{UV}$, where absorption due to brown carbon and dust became increasingly significant as a result of their greater wavelength-dependences. These mass absorption efficiencies from the UV to the IR hopefully will prove useful for future modeling purposes and the apportionment of gross optical properties.

Acknowledgements. We would like to acknowledge our funding agency (NASA, \#NNG04GC59G) and everyone involved in the planning and operation of this experiment. We also thank Russell Dickerson's group of the University of Maryland for their gas measurements. Finally, we thank the staff of the Xianghe IAP facility, who were exceedingly helpful and generous with their time and skills.

Edited by: Y. Balkanski

\section{References}

Alfaro, S. C., Lafon, S., Rajot, L., Formenti, P., Gaudichet, A., and Maille, M.: Iron oxides and light absorption by pure desert dust: An experiment study, J. Geophys. Res., 109, D08208, doi:10.1029/2003JD004374, 2004.

Ananth, G. and Wilson, J. C.: Theoretical analysis of the performance of the TSI aerodynamic particle sizer: The effect of density on response, Aerosol Sci. Tech., 9, 189-199, 1988.

Anderson T. L., Masonis, S. J., Covert, D. S., Ahlquist, N. C., Howell, S. G., Clarke, A. D., and McNaughton, C. S.: Variability of aerosol optical properties derived from in situ aircraft measurements during ACE-Asia, J. Geophys. Res., 108(D23), 8647, doi:10.1029/2002JD003247, 2003.

Anderson, T. L. and Ogren, J. A.: Determining aerosol radiative properties using the TSI 3563 integrating nephelometer, Aerosol Sci. Tech., 29, 57-69, 1998.

Andreae, M. O. and Gelencsér, A.: Black carbon or brown carbon? The nature of light-absorbing carbonaceous aerosols, Atmos. Chem. Phys. Discuss., 6, 3419-3463, 2006, http://www.atmos-chem-phys-discuss.net/6/3419/2006/

Arimoto, R., Zhang, X. Y., Huebert, B. J., Kang, C. H., Savoie, D. L., Prospero, J. M., Sage, S. K., Schloesslin, C. A., Khaing, H. M., and Oh, S. N.: Chemical composition of atmospheric aerosols from Zhenbeitai, China, and Gosan, South Korea, during ACE-Asia, J. Geophys. Res., 109, D19S04, doi:10.1029/2003JD004323, 2004. 
Arnott, W. P., Hamasha, K., Moosmuller, H., Sheridan P. J., and Ogren J. A.: Towards aerosol light-absorption measurements with a 7-wavelength aethalometer: evaluation with a photoacoustic instrument and 3-wavelength nephelometer, Aerosol Sci. Tech., 39, 17-29, 2005.

Bergstrom, R. W., Russell, P. B., and Hignett, P.: The wavelength dependence of black carbon particles: predictions and results from the Tarfox experiment and implications for the aerosols single scatter albedo, J. Atmos. Sci., 59, 567-577, 2002.

Birch, M. E. and Cary, R. A.: Elemental carbon-based method for monitoring occupational exposures to particulate diesel exhaust, Aerosol Sci. Tech., 25, 221-241, 1996.

Bond, T. C., Anderson, T. L., and Campbell, D.: Calibration and intercomparison of filter-based measurements of visible light absorption by aerosols, Aerosol Sci. Tech., 30, 582-600, 1999.

Bond, T. C. and Bergstrom, R. W.: Light absorption by carbonaceous particles: an investigative review, Aerosol Sci. Tech., 40, 27-67, 2006.

Bond, T. C., Covert, D. S., Kramlich, J. C., Larson, T. V., and Charlson, R. J.: Primary particle emissions form residential coal burning: optical properties and size distributions, J. Geophys. Res, 107(D21), 8347, doi:10.1029/2001JD000571, 2002.

Bond, T. C., Habib, G., and Bergstrom, R. W.: Limitations in the enhancement of visible light absorption due to mixing state, J. Geophys. Res., 111, D20211, doi:10.1029/2006JD007315, 2006.

Clarke, A. D., Kapustin, V. N., Howell, S., Shinozuka, Y., Moore, K., McNaughton, C.: Size distributions and mixtures of dust and black carbon aerosol in Asian outflow: Physiochemistry and optical properties, J. Geophys. Res., 109, D15S09, doi:10.1029/2003JD004378, 2004.

Clarke, A. D., McNaughton, C., Kapustin, V. N., et al.: Biomass burning and pollution aerosol over North America: Organic components and their influence on spectral optical properties and humidification response, J. Geophys. Res., 112, D12S18, doi:10.1029/2006JD007777, 2007.

Falkovich, A. H., Schkolnik, G., Ganor, E., and Rudich, Y.: Adsorption of organic compounds pertinent to urban environments onto mineral dust particles, J. Geophys. Res, 109, D02208, doi:10.1029/2003JD003919, 2004.

Fialho, P., Freitas, M. C., Barata, F., Vieira, B., Hansen, A. D. A., and Honrath, R. E.: The aethalometer calibration and determination of iron concentration in dust aerosols, Aerosol Science., 37, 1497-1506, 2006.

Fuller, K. A., Malm, W. C., and Kreidenweis, S. M.: Effects of Mixing on Extinction By Carbonaceous Particles, J. Geophys. Res., 014(D13), 15941-15954, 1999.

Hansen, A. D. A., Rosen, H., and Novakov, T.: The aethalometer - an instrument for the real-time measurement of optical absorption by aerosol particles, Sci. Total Environ. 36, 191-196, 1984.

Haywood J., Francis, P., Osborne, S., Glew, M., Loeb, N., Highwood, E., Tanre, D., Myhre, G., Formenti, P., and Hirst, E.: Radiative properties and direct radiative effect of Saharan dust measured by the C-130 aircraft during SHADE: 1. Solar spectrum, J. Geophys. Res, 108(D18), 8577, doi:10.1029/2002JD002687, 2003.

Hoffer, A., Gelencsér, A., Guyon, P., Kiss, G., Schmid, O., Frank, G. P., Artaxo, P., and Andreae, M. O.: Optical properties of humic-like substances (HULIS) in biomass-burning aerosols, Atmos. Chem. Phys., 6, 3563-3570, 2006, http://www.atmos-chem-phys.net/6/3563/2006/.

Huebert, B., Bertram, T., Kline, J., Howell, S., Eatough, D., and Blomquist, B.: Measurements of organic and elemental carbon in Asian outflow during ACE-Asia from the NSF/NCAR C-130, J. Geophys. Res., 109, D19S11, doi:10.1029/2004JD004700, 2004.

Kaufman, Y. J., Setzer, D., Ward, D., Tanre, D., Holben, D. N., Menzel, P., Pereira, M. C., and Rasmussen, R.: Biomass burning airborne and spaceborne experiment in the Amazons (BASE-A), J. Geophys. Res., 97, 14581-14599, 1992.

Kline, J., Huebert, B., Howell, S., Blomquist, B., Zhuang, J., Bertram, T., and Carrilo, J.: Aerosol composition and size versus altitude measured from the C-130 during ACE-Asia, J. Geophys. Res, 109, D19S08, doi:10.1029/2004JD004540, 2004.

Kirchstetter, T. W., Novakov, T., and Hobbs, P. V.: Evidence that the spectral dependence of light absorption by aerosols is affected by organic carbon, J. Geophys. Res., 109, D21208, doi:10.1029/2004JD004999, 2004.

Li, Z., Chen, H., Cribb, M., et al.: Preface to special section on East Asian Studies of Tropospheric Aerosols: An International Regional Experiment (EAST-AIRE), J. Geophys. Res., 112, D22S00, doi:10.1029/2007JD008853, 2007.

Novelli, P. C., Steele, L. P., and Tans, P. P.: Mixing ratios of carbon monoxide in the troposphere, J. Geophys. Res., 97(D18), 20, 731-20, 750, 1992.

Penner, J. E., Andreae, M., Annegarn, H., et al.: Aerosols, their direct and indirect effects, in Climate Change 2001: The scientific Basis: Contribution of Working Group I to the Third Assessment Report of the Intergovernmental Panel on Climate Change, edited by: Houghton, J. T., Nyenzi, B., Prospero, J., et al., Cambridge University Press, New York, USA, 291-348 2001.

Penner, J. E., Eddleman, H., and Novakov, T.: Towards the development of a global inventory for black carbon emissions, Atmos. Environ., 27, 1277-1295, 1993.

Putaud, J.-P., Van Dingenen, R., Dell'Acqua, A., Raes, F., Matta, E., Decesari, S., Facchini, M. C., and Fuzzi, S.: Size-segregated aerosol mass closure and chemical composition in Monte Cimone (I) during MINATROC, Atmos. Chem. Phys., 4, 889-902, 2004, http://www.atmos-chem-phys.net/4/889/2004/.

Reid, J. S., Jonsson, H. H., Maring, H. B., Smirnov, A., Savoie, D. L., Cliff, S. S., Reid, E. A., Livingston, J. M., Meier, M. M., Dubovik, O., and Tsay, S. C.: Comparison of size and morphological measurements of coarse mode dust particles from Africa, J. Geophys. Res., 108(D19), 8593, doi:10.1029/2002JD002485, 2003.

Schauer, J. J., Mader, B. T., DeMinter, J. T., et al.: ACE-Asia intercomparison of a thermal-optical method for the determination of particle-phase organic and elemental carbon, Environ. Sci. Tech., 37(5), 993-1001, 2003.

Schnaiter, M., Horvath, H., Möhler, O., Naumann, K.-H., Saathoff, H., and Schöck, O.: UV-VIS-NIR Spectral Optical Properties of Soot and Soot-containing Aerosols, J. Aerosol Sci., 34(10), 1421-1444, 2003.

Schnaiter, M., Linke, C., Mohler, O., Naumann, K., Saathoff, H., Wagner, R., Schurath, U., and Wehner, B.: Absorption amplification of black carbon internally mixed secondary organic aerosol, J. Geophys. Res., 110, D19204, doi:10.1029/2005JD006046, 2005. 
Sokolik, I. N. and Toon, O. B.: Incorporation of mineralogical composition into models of the radiative properties of mineral aerosol from UV to IR wavelengths, J. Geophys. Res., 104(D8), 94239444, 1999.

Solomon, S., Qin, D., Manning, et al.: Technical Summary, in: Climate Change 2007: The Physical Science Basis, Contribution of Working Group I to the Fourth Assessment Report of the Intergovernmental Panel on Climate Change, editet by: Solomon, S., Qin, D., Manning, M., et al., Cambridge University Press, Cambridge, UK, New York, USA, 2007.

Subramanian, R., Roden, C. A., Boparai, P., and Bond, T. C.: Yellow beads and missing particles: trouble ahead for filterbased absorption measurements, Aerosol Sci. Tech., 41, 630637, 2007.
Weingartner, E., Sathof, H., Schnaiter, M., Streit, N., Bitnar, B., and Baltensperger, U.: Absorption of light by soot particles: determination of the absorption coefficient by means of aethalometers, J. Aerosol Sci, 34, 1445-1463, 14537-14540, 2003.

World Meteorological Organization: A Preliminary Cloudless Standard Atmosphere for Radiation Computation, WCP-112 (World Climate Program), WMO/TD-NO. 24, Geneva, 1986.

Yang, M.: Separation of light absorption to black carbon, brown carbon, and mineral dust - interpretations of atmospheric measurements near Beijing, Master's Thesis, Dept. of Oceanography, University of Hawai'i at Manoa, 21-85, 2007.

Zhang, Y. and Carmichael, G. R.: The role of mineral aerosol in tropospheric chemistry in East Asia - a model study, J. Appl. Meteorol., 38(3), 353-366, doi:10.1175/1520-0450(1999)038, 1999. 